Review Article

\title{
The noninvasive assessment of maxillary sinus
}

\author{
Manish Munjal ${ }^{1 *}$, Ritu Gupta ${ }^{2}$, Porshia Rishi², Ajay Goyal ${ }^{2}$, Shubham Munjal ${ }^{1}$, \\ Shubham Garg', Archit Pal Singh ${ }^{2}$
}

${ }^{1}$ Department of ENT- Head and Neck Surgery, ${ }^{1,2}$ Dayanand Medical College, Ludhiana, Punjab, India

Received: 30 July 2020

Accepted: 05 September 2020

*Correspondence:

Dr. Manish Munjal,

E-mail: manishmunjaldr@yahoo.com

Copyright: (C) the author(s), publisher and licensee Medip Academy. This is an open-access article distributed under the terms of the Creative Commons Attribution Non-Commercial License, which permits unrestricted non-commercial use, distribution, and reproduction in any medium, provided the original work is properly cited.

\section{ABSTRACT}

The maxillary sinus with its antigravity drainage affected by pathology at the osteomeatal unit, necessitates an intervention, medical or surgical. Role of basic imaging in pretreatment evaluation is elaborated upon.

Keywords: Maxillary sinus, Computed tomography, Magnetic resonance imaging

\section{INTRODUCTION}

Radiography of the paranasal sinuses has been available since the early 1900s. These include skull radiographs, computed tomography and magnetic resonance imaging studies. The imaging studies play a crucial role in the prompt diagnosis and thus management of the maxillary sinus pathologies.

\section{RADIOGRAPHS OF THE SKULL}

In water's or occipitomental view, the maxillary antra are clearly visible. In caldwell's or occipitofrontal view, the upper portion of the antra are obscured by the petrous bones but their lower parts are visualised. On the lateral projection, the paired sinuses are superimposed on each other, but the extent of pneumatisation of the sinuses can be assessed. ${ }^{1}$ The radiation exposure for water's and lateral view radiographs is $40-60 \mathrm{mSv}^{2}$ Role of sinus radiographs is very controversial with false positive and false negative interpretations. Normal sinuses are radiolucent, whereas diseased sinuses show varying degrees of opacity or air fluid level. ${ }^{2}$ Moreover, sinus radiographs are not reliable components of clinical decision making process and do not accurately evaluate disease of the sinuses and their drainage pathways because of the overlapping structures, Lazar et al, Goldstein and Philips. ${ }^{3,4}$

\section{COMPUTED TOMOGRAPHY (CT) AND MAGNETIC RESONANCE IMAGING (MRI) OF MAXILLARY SINUS}

Computed tomography and magnetic resonance imaging are the modalities of choice for delineating maxillary sinus pathology and potential maxillary sinus malignancies, with arteriography reserved for the occasional highly vascular tumour. In general, malignancies erode bone, whereas benign processes cause reactive thickening or remodelling of adjacent bone. Computed tomography is the most practical costeffective means to study the paranasal sinuses and assists in avoiding complications. Computed tomography scans typically obtained for visualizing the paranasal sinus should include coronal and axial $(3 \mathrm{~mm})$ cross sections.

Soft tissue and bony windows facilitate evaluation of disease processes and the bony architecture. The use of intravenous contrast material just prior to scanning can help define soft tissue lesions and delineate vascularized structures, such as vascular tumors. Contrast-enhanced computed tomography is particularly useful in evaluating neoplastic, chronic, and inflammatory processes., ${ }^{5,6}$ 
However, for most patients with sinusitis, non-contrast computed tomography of the paranasal sinuses generally suffices. Patients who may not tolerate the prone position required for coronal cuts; computer-generated reconstructed coronal views can be generated from thin axial sections. ${ }^{7}$ Proper positioning of the patient's head is important to obtain computed tomography images. In axial views, the patient's hard palate is placed perpendicular to the CT scanner table. The images are obtained such that the external auditory canal is in line with the inferior orbital rim. The coronal images are taken so that the gantry is perpendicular to the patient's hard palate. Misalignment or rotation can lead to distortion of the true anatomy on the films. ${ }^{8}$ Computed tomography of paranasal sinuses is used in correlation with clinical examination procedures, including nasal endoscopy. The diagnostic field of the scan for detecting irreversible (surgically treatable) disease processes. Such as chronic disease or structural problems, is increased once acute or reversible problems are treated. As such, Computed tomography scans should be obtained only after acute sinusitis episodes have been adequately treated so that acute inflammation is not mistaken for chronic mucosal disease. ${ }^{8}$ Apart from anatomical status, computed tomography is used to assess the pathological status of paranasal sinuses. Delineation of pathology, site and extent, depth or invasion, details of mucosal abnormalities, possible cause of pathology. In Figure 1 axial section showing bilateral pneumatised maxillary sinuses.

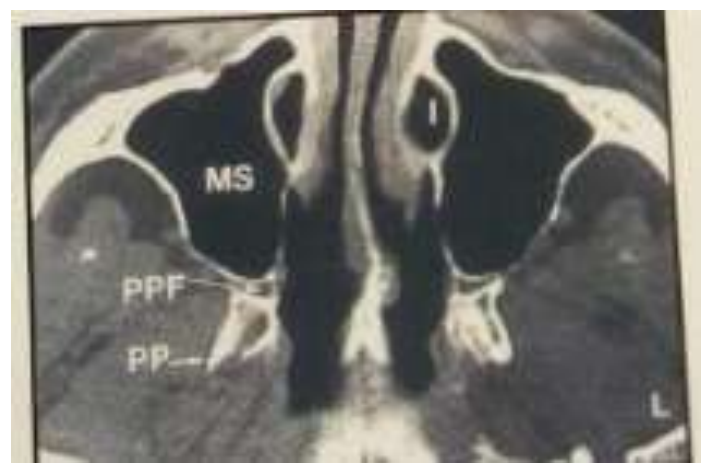

Figure 1: Axial section showing bilateral pneumatised maxillary sinuses.

In (Figure 2) coronal section showing bilateral pneuma tised maxillary sinus.

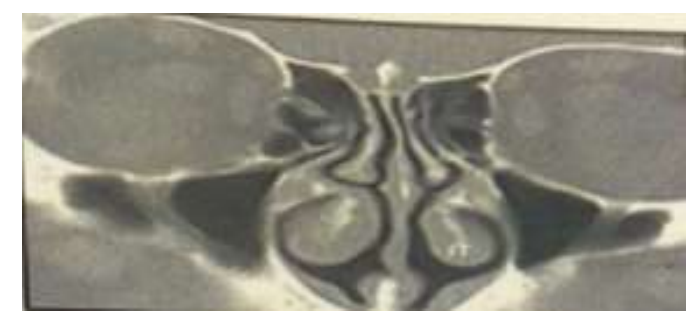

Figure 2: Coronal section showing bilateral pneumatised maxillary sinus.
Computed tomography scanning can be helpful in the diagnosis of acute and chronic sinusitis, neoplastic and inflammatory processes, and other problems (eg, congenital anomalies).

Acute sinusitis-computed tomography findings are sinus opacification, air-fluid levels and thickened localized mucosa. Many nonspecific computed tomography findings, including thickened turbinates (nasal cycle vs allergic process vs inflammation) or diffusely thickened sinus mucosa (allergic disease vs chronic sinusitis), may be associated with several sinonasal conditions. ${ }^{7}$ Chronic sinusitis-computed tomography findings include mucosal thickening, opacified air cells, bony remodelling, and bony thickening due to inflammatory osteitis of the sinus cavity walls. Bony erosion can occur in severe cases, especially if associated with massive polyps or mucoceles. $^{7}$

Sinonasal polyps- These appear on Computed tomography scans as nodular or rounded masses and amorphous opacified blobs of tissue. Bony remodelling can occur, but it is typically subtle, which is expected from the usual slow growth pattern of sinonasal polyps and benign processes in general. ${ }^{7}$

Computed tomography is very reliable in demonstrating erosion of the bony sinus wall or peri sinus extension, Pearlman et al. ${ }^{9}$ Over the years, it has established its place as the "investigation of choice" for evaluation of paranasal sinus pathology. Soft tissues of the orbit and anterior cranial fossa can also be visualised, Smith and Smith. ${ }^{10}$ Extra cranial extension is a hallmark of malignant disease. It may represent a primary sinus tumour, a metastatic lesion or extension of intracranial neoplasm, Lawson and Renio. ${ }^{11}$ Coronal study of Maxillary Sinus is used to assess: alignment of the septum, uncinate process -aplasia/ hypoplasia, medial/ lateral deflection, pneumatization, hypertrophy, attachment of the middle turbinate, variations of the middle turbinate, such as the presence of a concha bullosa, width of the infundibulum, degree of pneumatization of the maxillary sinus, size and status of the maxillary sinuses (hypoplastic vs normal size), patency of the ostiomeatal complex, relationship of cells within the frontal recess and their relationship to the frontal sinuses, status of the lamina papyracea, dehiscence in the lamina papyracea, shape of the medial orbital wall, depth of the olfactory fossa: the deeper the fossa (i.e., increased distance from the cribriform plate and the fovea ethmoidalis), the higher the chance for fracture or perforation with surgical manoeuvres, slope, thickness, and asymmetries in the height of the ethmoid roof.

The prevalence of intracranial penetration during Functional Endoscopic Sinus Surgery is higher when this anatomic variation occurs. Intracranial penetration is more likely to occur on the side with the lower roof. Vertical distance from the maxillary sinus to the ethmoid 
roof in posterior ethmoid cells. Coronal plane is the preferred plane for computed tomography imaging prior to functional endoscopic sinus surgery because being synchronized with surgical steps, it serves as a guide (roadmap) to the endoscopist. The optimal technique consists acquiring direct continuous sections $3 \mathrm{~mm}$ thick in the coronal plane, Kennedy et al. ${ }^{12}$

Axial study of Maxillary Sinus is used to assess: alignment of the septum, position of uncinate (medial versus lateral), patency of the ostiomeatal complex, patency of the $\mathrm{V}$-shaped ethmoidal infundibulum, depth and ratio of the anterior and posterior ethmoid cells compared, to the sphenoid sinus, degree of pneumatization of the sphenoid sinus, position of sphenoid inter sinus septae, presence or absence of an onidi cell (sphenoethmoidal cell), degree of indentation created by carotid artery and optic nerve, dehiscence in the bony covering of carotid artery or optic nerve, relationship of the optic nerve to the posterior ethmoid cells, the presence of anterior clinoid process pneumatization.

Disadvantage of the computed tomography scan include higher expenses, higher radiation dose and interference by artifacts such as extensive dental fillings Stammberger and Hawke. ${ }^{13}$ In the Figure 3, large agar nasi cell (AN) is mentioned. and in the Figure 4, accessory maxillary ostium is mentioned.

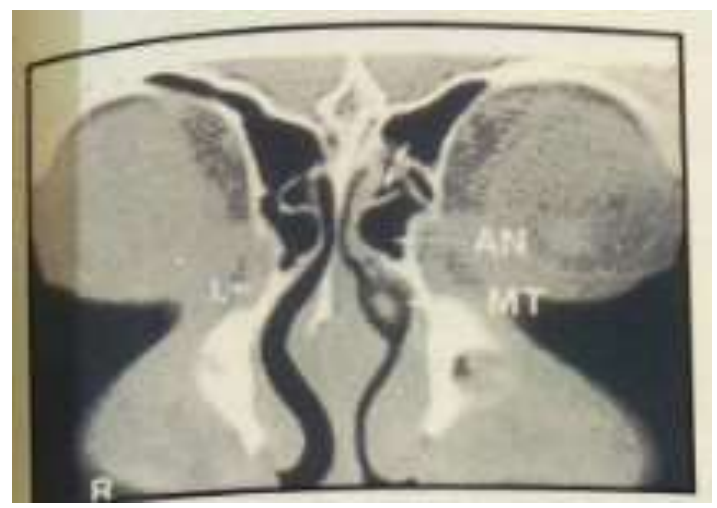

Figure 3: Large agar nasi cell (AN).

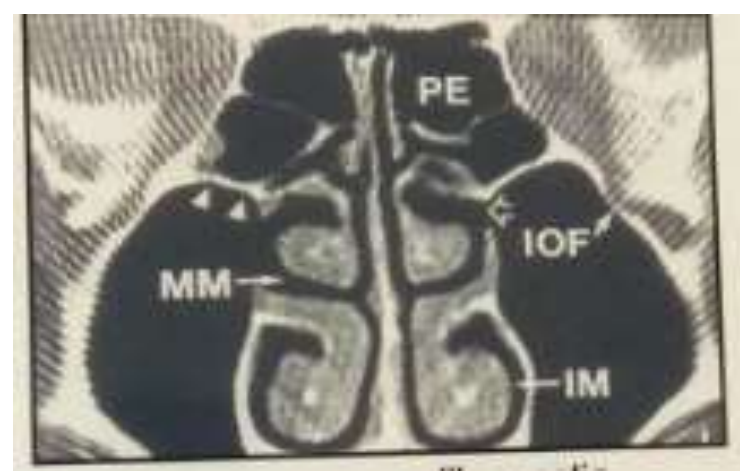

Figure 4: Accessory maxillary ostium.

\section{MAGNETIC RESONANCE IMAGING}

Magnetic resonance imaging (MRI) gives an excellent delineation of soft tissue lesions and important structures adjacent to maxillary sinus; although it cannot differentiate between benign and malignant processes. Inflammed mucosa, polyps and non-inspissated secretions with high water content have increased signal intensity on $\mathrm{T} 2$ weighted images whereas neoplasms have interme diate signal intensity. Some sinonasal malignancies like minor salivary gland tumours, schwannomas, and haemangiomas exhibit high signal intensity on T2 weighted images. ${ }^{8}$

\section{MAGNETIC RESONANCE IMAGING VERSUS COMPUTED TOMOGRAPHY}

Magnetic resonance imaging is superior to Computed tomography in differentiating tumour from the adjacent inflammatory sinus disease. If complication of sinusitis or a neoplasm is suspected, the study of choice is contrast enhanced Magnetic resonance imaging.

Other advantages are: multiplanar capability, Superior soft tissue contrast, Lack of ionizing radiations. The standard protocol for Magnetic resonance imaging of paranasal sinuses is T1 weighted images in the axial, coronal and saggital planes; and $\mathrm{T} 2$ weighted images in the axial plane. T1 weighted images assess anatomy; T2 weighted images assess disease.

Brighter signal is produced by fluid containing structures whereas a lower Signal is produced by a malignant tumours. ${ }^{8}$

Disadvantages of MRI are: long procedure as compared to computed tomography scan, which Takes approximately 15 minutes, magnetic resonance imaging confine the patient is more noisy than computed tomography machine, and therefore claustrophobic patients are difficult to assess, the bony demarcation of the sinuses appear as a plane of absent signal on Magnetic resonance imaging. Therefore, it is not a reliable road map to guide the surgeon during functional Endoscopic Sinus Surgery, Oliverio and Zinrcich. ${ }^{14}$

\section{CONCLUSION}

Vis a vis imaging is the road map to the functional endoscopic sinus surgery of the maxillary sinus.

Funding: No funding sources

Conflict of interest: None declared

Ethical approval: Not required

\section{REFERENCES}

1. Phelps PD. Radiology of the Nose and Paranasal Sinuses. In: Mackay and Bull, editors. Scott 
Brown's Otorhinolaryngology, Head and Neck Surgery. $6^{\text {th }}$ edition. London: Elsevi. 1997;4(3):2.

2. Gray. Nose, nasal cavity and paranasal sinuses. In: Gray's Anatomy The anatomical basis of clinical practice. 37th ed. London; 1993.

3. Lazar Rh, Younis RT, Long TE. Functional endoscopic sinus surgery in adults and children. Laryngos. 1993;103:1-5.

4. Goldstein JH, Philips CD. Current indications and techniques in evaluating inflammatory disease and neoplasia of the Sinonasal cavities. Curr Probl Diagn Radio. 1998;27:41-71.

5. Yousem DM. Imaging of sinonasal inflammatory disease. Radiolol. 1993;188(2):303-4.

6. Blanton PL, Biggs NL. Eighteen hundred years of controversy: the paranasal sinuses. Am J Anat. 1969;124(2):135-47.

7. Shankar L, Evans K. The radiological features of inflammatory diseases. In: An Atlas of Imaging of the Paranasal sinuses. 2nd edition. UK: Informa healthcare; 2005; 93-100.

8. Som PM, Shugar J.MA, Brandwein MS. Anatomy and physiology.In: Som PM, Curtin HD, editors. Head and Neck imaging. 4th ed. Missouri: Elsevi. 2003;123:101-3.
9. Pearlman SJ, Lawson W, Billet HF, Friedman WH, Potter GD. Isolated sphenoid sinus disease. Laryngos. 1989;99:716-20.

10. Smith MM, Smith TL. Imaging of the paranasal sinuses for functional endoscopic sinus surgery: Minimally Invasive Surgery of the Head, neck and cranial base. Lippin Williams Wilki. 2002;212.

11. Lawson W, Reino AJ: Isolated sphenoid sinus disease: An analysis of 132 cases. Laryngos. 1997;107:1590-5.

12. Kennedy DW, Bolger WE, Zinreich SJ. Diseases of the sinuses, Diagno Managem. 2006; 216.

13. Stammberger H, Hawke M. Basic Principles of Functional Endoscopic Sinus Surgery. In: Essenti Endosco Sinus Surg. 1993: 2.

14. Oliverio PJ and Zinreich SJ: radiology of the nasal cavity and paranasal sinuses. In Otolaryngology Head and Neck Surgery Volume 2. 3rd edition. by Mosby year book, Inc; 1998.

Cite this article as: Munjal M, Gupta R, Porshia Rishi P, Goyal A, Munjal S, Garg S, et al. The noninvasive assesment of maxillary sinus. Int $\mathrm{J}$ Otorhinolaryngol Head Neck Surg 2020;6:1947-50. 